"GEO Revista Eletrônica do Curso de Geografia do Campus Avançado de Jataí-GO www.jatai.ufg.br/geo/geoambiente.htm

\title{
GEOGRAFIA SÓCIO-AMBIENTAL OU GEOGRAFIA DO MEIO
}

\section{AMBIENTE?}

João Mateus de Amorim ${ }^{1}$

(1 - Professor de Geografia - Escola Agrotécnica Federal de Uberlândia mateusamorim@terra.com.br)

\section{RESUMO}

Este artigo faz uma análise da geografia ambiental, com o objetivo de analisar a sua relação com o desenvolvimento sustentável. Essa análise também permitirá estabelecer possíveis discussões, com vistas, ao entendimento das ações humanas sobre o espaço geográfico. O viés de discussão deste trabalho está amparado nos aspectos sustentáveis englobando várias dimensões de análise, tais como: a ambiental, a econômica, a social, a cultural, a espacial e a política. E também no entendimento de CAPRA (1982); MORIN (2003) e MENDONÇA (1993).

Palavras Chave: Desenvolvimento Sustentável, Gestão Democrática, Geografia Sócio-. Ambiental.

\section{ABSTRACT \\ PARTNER-ENVIRONMENTAL GEOGRAPHY OR GEOGRAPHY OF THE ENVIRONMENT?}

This article makes an analysis of the environmental geography, with the objective of analyzing its relationship with the maintainable development. That analysis will also allow establishing possible discussions, with views, to the understanding of the human actions on the geographical space. The inclination of discussion of this work is aided in the maintainable aspects including several analysis dimensions, such as: the environmental, the economic, the social, the cultural, the space and the politics. It is also in the understanding of CAPRA (1982); MORIN (2003) and MENDONÇA (1993).

Keywords: Maintainable development, Democratic Administration, Partner-environmental Geography. 


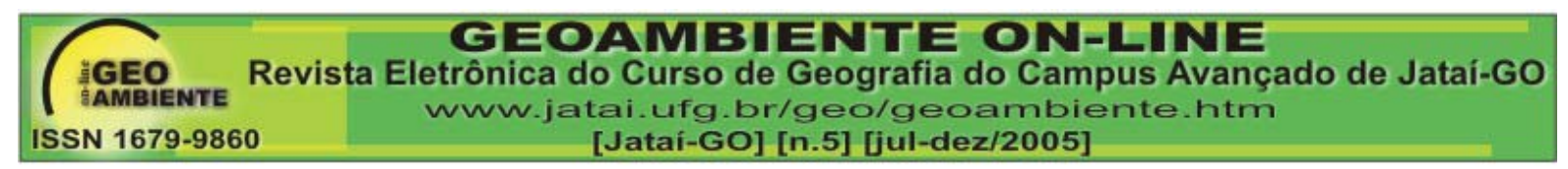

\section{Introdução}

Há neste artigo uma tentativa de explicar a questão sócio-ambiental como um todo (Holística) e a sistêmica de Capra (1982) perpassando pela geografia. Pretendemos, ainda, analisar essa discussão no entendimento da inter-trans-multidisciplinaridade de Morin (2004) que discute a quebra de barreiras entre as disciplinas. Portanto, fica uma indagação? Será que a geografia ambiental não está em duplicidade? Por que - "a priori”, a geografia já garante a discussão do meio ambiente?

$\mathrm{O}$ meio ambiente urbano está em crise devido às ações predatórias do homem. Nos ambientes urbanos os espaços da vegetação natural foram quase todos modificados, restando somente uma segunda natureza ${ }^{1}$. As modificações nos espaços naturais urbanos provocam uma crise sócio-ambiental, na medida em que, só ocorrerá a vida na relação entre a natureza e a sociedade. A natureza é condição essencial para a reprodução humana na terra, ou seja, trata-se de permitir às gerações futuras condições de habitabilidade no planeta terra.

Isso só ocorrerá com a promoção do desenvolvimento sustentável, da educação ambiental e da gestão democrática. A inter-relação entre esses três temas aumenta as possibilidades de atender aos futuros anseios por qualidade de vida, sobrevivência e boas condições de habitabilidade.

\section{Desenvolvimento Sustentável}

No desenvolvimento sustentável e na sustentabilidade, há a necessidade de gestão democrática, de educação ambiental, de cidadania e de participação política da sociedade. $\mathrm{O}$ desenvolvimento sem correlação com esses fatores, com base no aspecto econômico, será considerado como um crescimento econômico, por si só, sem nenhuma preocupação com aspectos sociais ou ambientais (DELGADO, 1985). Assim sendo, ao analisar, este viés, há a necessidade de uma avaliação mais rigorosa acerca do desenvolvimento, pois, o país pode aumentar o PIB sem distribuir este crescimento ${ }^{2}$. Isso agravou ainda mais os problemas sócioambientais, pois onde há pobreza há degradação ambiental.

\footnotetext{
${ }^{1}$ Ao alterar e modificar a natureza, ou seja, a primeira natureza "natural", a humanidade, passa-se a conviver com uma segunda natureza alterada ou aculturada pelo homem.

${ }^{2} \mathrm{O}$ crescimento do PIB desvinculado de outras políticas sociais ou ambientais não garante desenvolvimento com qualidade de vida para todos, e sim, um crescimento econômico de poucas pessoas. A palavra desenvolvimento, neste contexto abarca todas as dimensões da sustentabilidade ambiental, social, econômica, cultural e política possibilitando qualidade de vida para toda a sociedade.
} 
O desenvolvimento sustentável deve dar enfoque à gestão democrática, com a necessidade de uma gestão pública ampliada com vários setores da sociedade, do mercado e do poderes públicos locais. Mas as experiências brasileiras demonstram a concentração nos investimentos de cunho econômico, e sem a preocupação com os aspectos ambientais e sociais.

\begin{abstract}
Uma política pública é um conjunto de decisões inter-relaionadas, tomadas pó um gestor ou por um grupo de gestores a respeito de objetivos e metas traçadas, a priori, por gestores públicos, visando a operacionalizar um curso de ação. Políticas públicas ambientais são formuladas por gestores públicos objetivando garantir a sustentabilidade dos recursos ambientais. Na formulação de políticas públicas, a regra tradicional para se estimar benefícios e danos ambientais está calcado na análise de alternativas de investimentos. Ocorre que os principais manuais que têm influenciado o trabalho de avaliação econômica de projetos não contemplam a dimensão ambiental (GEORGIOU, et al, 1997 apud MOTA, 2001, p.53).
\end{abstract}

De acordo com essa abordagem, Santos (1996) aponta os elementos necessários para que haja uma cidadania plenamente constituída quando:

- o Estado implementar políticas públicas em todos os espaços territoriais;

- as populações pobres tiverem direito à palavra como membro ativo;

- a geografização, da cidadania, atender a todos os indivíduos nos direitos territoriais, culturais, direito à educação, ao lazer, à moradia e emprego para viver com dignidade;

- a cidadania deve abranger a todos os territórios de forma igualitária, sem excluir os espaços periféricos e distantes dos centros de consumo (periferia urbana e a região nordeste no Brasil).

A partir desses fatos, pode-se começar a discutir a gestão democrática, pois, sem isso, não há como traçar nenhum projeto de desenvolvimento. A execução de um projeto de desenvolvimento sustentável deve se pautar na cidadania, na democracia e na participação da sociedade como um todo. O contrário seria um simples projeto de crescimento econômico ditado de "cima para baixo" e de "fora para dentro", sem uma prévia discussão com a comunidade local, agravando as questões sócio-ambientais. Uma sociedade educada, cidadã, 


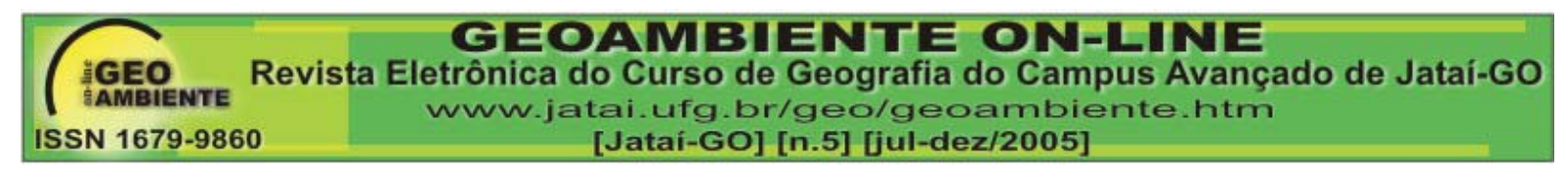

será mais politizada, organizada e mais reivindicativa dos seus direitos, tais como: direito à cidade $^{3}$, aos espaços rurais, ao bem-estar, ao ambiente equilibrado, à qualidade de vida. Assegurados os direitos, a sociedade pressionará tanto as empresas quanto o poder público nas tomadas de decisão, de forma mais harmônica com a natureza e com os aspectos humano, cultural, social, institucional, espacial e político. E, também pressionará os empresários a produzirem dentro dos padrões ecológico-sustentáveis, principalmente deixando de comprar de fornecedores que produzam de forma insustentável.

Para compreender melhor como se deu o processo de dominação e concentração em nosso país é preciso fazer uma historicização dos acontecimentos. Acselrad (2001) contextualiza a questão da apropriação dos recursos naturais no Brasil e também a concentração do poder econômico nas mãos de uma elite ${ }^{4}$ preocupada, somente no aspecto econômico. Esse processo iniciou-se com a conquista colonial, estabelecendo aí, uma situação extrema de exclusão, escravidão, degradação ambiental e depleção dos recursos naturais comandada por esta classe $\mathrm{e}^{5}$ dominante preocupada somente com o lucro.

A partir de 1850, com a lei de terras, esse processo se acirrou ainda mais, pois, excluiu tanto os escravos quanto os trabalhadores livres, do acesso à terra. Isso aprofundou as possibilidades de uma reforma agrária ampla com base na pequena produção agrícola, agravando, também, a questão social e ambiental. A partir desse contexto começou a intensificar os problemas urbanos - sócio- ambientais e saúde pública, principalmente, na capital do país, Rio de Janeiro, no início do século XX, devido ao processo de exclusão dos cidadãos à terra. Com a industrialização e urbanização do país, pós 1930, de forma rápida e intensificada, e que provocou um processo de intensa agressão ao ser humano e à natureza. Mas, foi a partir da década de 1960, que esses aspectos agravaram, ainda mais, com a modernização e mecanização do campo (tratores, silos, técnicas agrícolas, irrigação, agroindústrias, metereologia, agrotóxicos, sementes melhoradas e agências de pesquisas) de acordo com (MÜLLER, 1989; DELGADO, 1985). Essa mecanização, nos espaços rurais,

\footnotetext{
${ }^{3} \mathrm{O}$ direito à cidade será consolidado, quando, todos os cidadãos urbanos tiverem acesso a todos os equipamentos de infra-estrutura (asfalto, luz, água encanada, esgoto, segurança, escolas, lazer, aspectos culturais, arborização e ambiente não poluído). A terra urbana está atrelada ao capitalismo imobiliário, sendo assim, exclui, marginaliza e impede aos pobres dos bairros periféricos o direito de desfrutar da cidade com qualidade de vida.

${ }^{4}$ A elite do nosso país são resquícios da oligarquia latifundiária que tornou se a partir de 1930 com a industrialização e urbanização do Brasil empresários e industriais. Estes fazem parte da política e do poder econômico em nosso país.

${ }^{5}$ A classe dominante é composta pelos detentores dos meios de produção (empresários e industriais) e de políticos.
} 
provocou a expulsão dos trabalhadores e pequenos produtores rurais para as cidades provocando um inchaço urbano ${ }^{6}$ nas principais capitais do país. E por fim, a partir da década de 1990, em face da ganância por lucros rápidos a natureza não conseguiu acompanhar o ritmo da exploração do sistema capitalista, de cunho neoliberal e ancorado na globalização, que enfatiza a cultura do consumo apresentado na mídia televisiva e outros canais de comunicação. Essa exploração intensa causa impactos ao meio ambiente. A natureza não consegue repor e recompor as ações humanas nesses espaços, pois o tempo da natureza é lento enquanto que o tempo do capital é rápido.

Dois processos caracterizaram a partir da territorialidade do capitalismo brasileiro. O primeiro diz respeito à concentração crescente do poder de controle dos recursos naturais nas mãos de poucos agentes. [...] O segundo processo característico da territorialidade capitalista brasileira é o de privatização do uso do meio ambiente comum, mais especificamente do ar e das águas de que dependem todos os grupos humanos. A reprodução da moderna sociedade capitalista no Brasil, com sua particular modalidade de "fordismo", se baseou na aceleração dos ritmos de produção e na intensificação do trabalho. Por necessidade de geração de lucros crescentes, mediante a acumulação intensiva, foi permanente o esforço em aumentar a velocidade de recuperação do capital investido, fazendo com que tal aceleração acabasse por se chocar com os ritmos, mais lentos, de regeneração próprios aos indicadores qualitativos do meio físico (ACSELRAD, 2001, pp.76-77)

As políticas públicas face aos direitos ambientais da população acabam ficando em segundo plano, a partir da forte intervenção e posicionamentos dos interesses dominantes das áreas de infra-estrutura do nosso país. Isso acaba institucionalizando os grandes projetos de investimento público com o slogan "meio ambiente único" de acordo com Acselrad (2001), ou seja, com a finalidade de contemplar, somente, os agentes do grande capital.

Esse processo, em torno dos investimentos públicos, com o privilégio da classe dominante, principalmente o grande capital internacional deu-se com mais intensidade no Brasil nos anos do período autoritário (de 1964 a 1985). Os movimentos sociais foram os maiores questionadores dessa situação, porém, foram fortemente atacados pela repressão do

\footnotetext{
${ }^{6}$ Inchaço urbano é a concentração de populações nas cidades sem nenhuma infra-estrutura para garantir um mínimo de qualidade de vida. Assentamentos urbanos de pessoas excluídas do campo, sem planejamento. Este fenômeno gerou em várias capitais a metropolização, sem uma urbanização prévia dos espaços urbanos.
} 


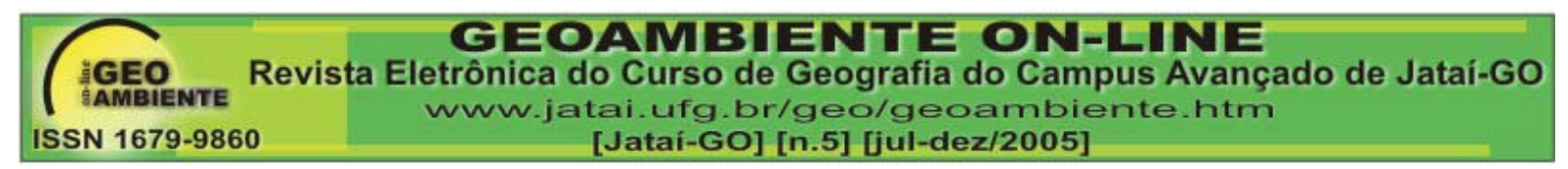

Estado ditatorial. Acselrad (2001, pp.81-83) enumera alguns questionamentos dos movimentos sociais acerca da posição desse Estado autoritário. E com isso faz um contraponto à gestão de cunho democrático com ampla liberdade de expressão, cidadania, politização e participação popular em todos os encaminhamentos do poder público local face às políticas públicas de Estado.

- Distribuição econômica e populacional de forma igualitária no espaço geográfico brasileiro;

- atendimento efetivo nas áreas pobres com vistas a diminuir as migrações no espaço;

- democratização do acesso a terra nos espaços rurais e acompanhamento dos conflitos acerca da terra;

- a viabilização da agricultura familiar com base no incentivo da produção de alimentos mais barato para as populações mais pobres;

- o zoneamento ecológico-econômico com a efetivação do desenvolvimento sustentável dos territórios, e também, o respeito às vocações das populações locais.

Essas ações, somadas a outras, fortalecem as identidades e as vocações, e também estimulam a cidadania e a participação coletiva, aumentando as possibilidades do fortalecimento da gestão democrática.

De acordo com esse enfoque no que tange as políticas ambientais, Acselrad (2001, p.84) faz uma reflexão da crise do Estado face ao não atendimento ao meio ambiente.

- Incapacidade e desmontagem do sistema de fiscalização, administração de unidades de conservação e falta de equipamentos adequados para o trabalho;

- estrangulamento das atividades que dependiam direta ou indiretamente da liberação de recursos orçamentários contingenciados (Fundo Nacional de Meio ambiente);

- esvaziamento gradual dos òrgãos colegiados como o CONAMA, e outros conselhos relacionados ao meio ambiente;

- pulverização das políticas em vários projetos setoriais ou regionais com base em recursos externos; 


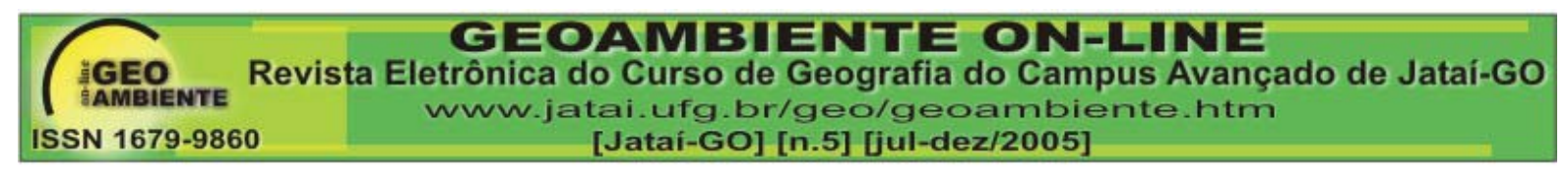

- execução de projetos ambientalmente danosos ao meio ambiente (plantações homogênias de eucalipto e tolerância de indústrias “sujas").

- incapacidade de dar conta do agravamento das condições sanitárias do país (por exemplo, a mudança em determinados padrões de doença prevalecentes no país: as doenças associadas à pobreza).

Diante desses fatos pode-se confirmar que o Estado nos últimos anos preocupou-se, somente, com os aspectos econômicos, deixando de lado os aspectos sócio-ambientais.

[...] Pois o fato é que o mercado tem se mostrado renitentemente incapaz de regular a complexidade dos processos sociológicos, apenas se restringindo a reduzir cada porção do espaço ao simples valor que ele encerra para os atores centrais da reestruturação global. [...] $\mathrm{Na}$ verdade, a fragmentação e a pulverização das instâncias de decisão da política ambiental exprimem o fato de que a questão ambiental não é ainda uma questão de Estado no Brasil. . [...] O meio ambiente é visto por vezes como uma simples restrição a ser acrescida ao conjunto das políticas públicas [...] para o programa avança Brasil de investimentos 2000-2003, o meio ambiente é exibido como 'oportunidade de negócios (ACSELRAD, 2001, pp.8688).

\section{Sustentabilidade}

Na visão de Sachs (1993) apud Barbieri (1997) devemos adotar uma abordagem ampla para a discussão a respeito da sustentabilidade. Isto traça um conceito em várias dimensões para a discussão da sustentabilidade. Esse processo joga por terra o conceito antigo que só explicava os fluxos naturais, sem preocupação com outras dimensões da sustentabilidade, como:

- sustentabilidade social- preocupação com os direitos e redução das desigualdades sociais entre as populações;

- sustentabilidade econômica- gestão eficiente de recursos e investimentos nos projetos de desenvolvimento;

- sustentabilidade ecológica- redução do consumo de recursos naturais e a produção de resíduos, e tecnologias limpas e poupadoras de recursos e sua adequação para a proteção ambiental; 


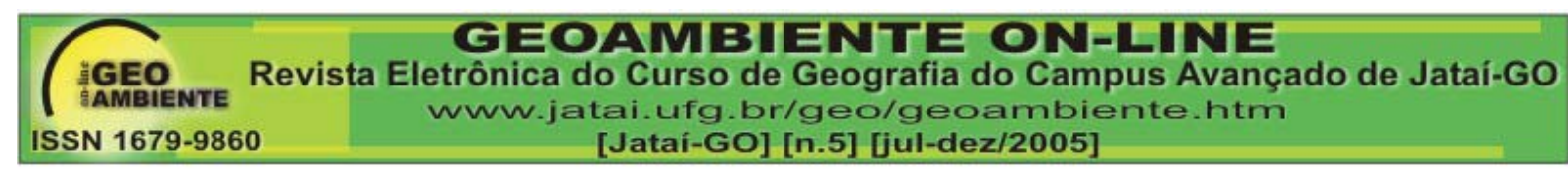

- sustentabilidade espacial- equilíbrio entre o rural e o urbano e uma melhor distribuição do território e a preocupação com a concentração metropolitana;

- sustentabilidade cultural- respeito às peculiaridades locais, cultura e de cada ecossistema.

Goodland (2001, p.293) aborda que a maior parte do meio ambiente encontra-se fora dos mercados (ar saudável, biodiversidade, clima estável), ou seja, externalizado pela economia. Nesse contexto, exige-se de toda a sociedade uma atitude contrária às práticas insustentáveis do mercado ao meio ambiente. Caso contrário ocorrerá à degradação da nossa natureza, e também, a das futuras gerações. Então, devem se promover mudanças de estilos de vida e de hábitos de consumo na busca da sustentabilidade, de acordo com (GOODLAND 2001, p. 293).

- Andar a pé, de bicicleta e de transporte coletivo;

- abrir janelas custa menos do que ligar ar condicionado;

- reciclar custa menos do que jogar no lixo;

- durabilidade custa menos do que a obsolescência;

- pequenas famílias custam menos do que grandes famílias;

- diminuição do consumo;

- dietas a base de grãos;

- a prevenção da poluição e do lixo causa menos danos que seu tratamento;

- o crescimento intensivo em trabalho custa ambientalmente menos do que o crescimento intensivo em capital;

- a insolação custa menos do que acender o forno;

- mais cobertores causa menos mal que aumentar o termostato;

- mudanças no estilo de vida promovem a melhoria da sustentabilidade ambiental.

Ainda de acordo com esse enfoque (GOODLAND, 2001, p.294) apontamos as prioridades para a sustentabilidade ambiental, em ambientes urbanos:

- saneamento de baixa tecnologia, sanitários com fossas;

- encanamento de fabricação local;

- trabalho cooperativo; 


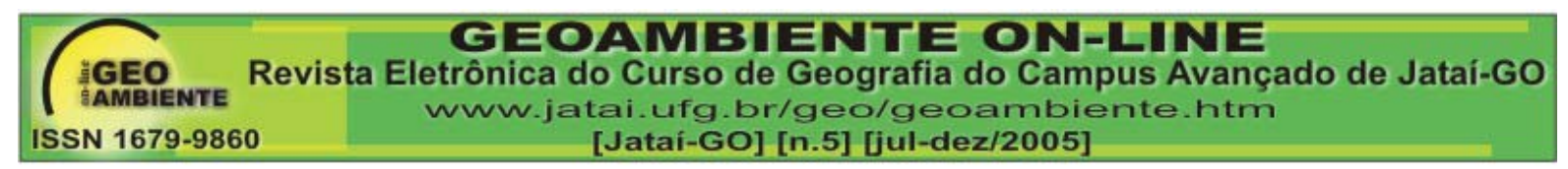

- redução de perda de água potável nas favelas;

- promoção de combustíveis mais limpos (metanol e carvão vegetal);

- o uso de forno e fogão solar;

- digestores de biogás/metano e lixo;

- evitar geração de lixo em vez de tratá-lo;

- promoção de cooperativas nas favelas;

- lojas com preços justos e comércio limpo: subsídios aos cereais básicos;

- campanhas educativas de saúde, higiene, aleitamento materno e planejamento familiar;

- assistência médica preventiva: vacinas e reidratação oral;

- assistência jurídica orientadora para obtenção de benefícios e com barreira à usura e outros abusos;

- organização social e ação coletiva dos pobres para gestão melhorada de recursos.

\section{Cúpula da Terra}

A Agenda 21 também discute a sustentabilidade e propõe mudanças de hábitos e costumes da sociedade de consumo. Podemos perceber o quanto a sociedade, o poder público, as ONGs, o mercado precisam fazer para que as gerações futuras possam contemplar a natureza e também obter recursos para a sobrevivência.

A conferência das Nações Unidas sobre o Meio Ambiente e Desenvolvimento CNUMAD - composta de 178 países e o Fórum Global das ONGs (4 mil unidades) reuniramse em um evento denominado de RIO 92. Esses dois eventos foram chamados de ECO-92. Dessa reunião nasceu a Agenda 21 e vários documentos, protocolos, declarações e convenções acerca do meio ambiente. Os documentos oficiais aprovados nessa conferência são os seguintes de acordo com Barbieri (2001, p. 47-48).

- Declaração do Rio de Janeiro sobre o Meio Ambiente e o Desenvolvimento;

- convenção sobre Mudanças Climáticas;

- declaração de princípios sobre florestas;

- convenção de Biodiversidade;

- a Agenda 21. 


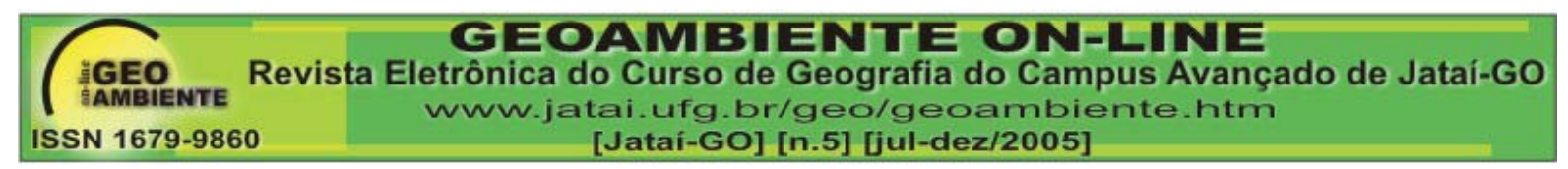

A realização desta conferência contribuiu para o conhecimento e a pesquisa de vários temas relacionados ao meio ambiente, de forma geral. Isso fez entender a real necessidade de mudarmos as nossas atitudes para que o presente século tenha um meio ambiente equilibrado e uma melhor qualidade de vida para toda a sociedade. Esse tema abarca os principais desafios para a implantação da sustentabilidade no planeta terra.

\section{Geografia e Meio Ambiente}

Segundo Nehme (2004), até 1960, a Geografia preocupava-se, somente, em descrever o quadro natural, compartimentado, ou seja, relevo, clima, vegetação e hidrografia. A partir desta data surge a geografia humanista de cunho marxista preocupada com as relações sociais de produção e a estrutura de classes, porém sem preocupação com as questões ambientais. No Brasil, a temática ambiental, destaca-se com a constituição de 1988 que implementou e normatizou as ações ambientais através dos estudos de impactos ambientais e relatórios de impactos ambientais (EIA - RIMA).

[...] geografia e meio ambiente-resulta tanto de uma reflexão construída ao longo dos últimos vinte anos a partir de leituras, debates e experiência profissional como de inquietações decorrente da crescente imersão de numerosos geógrafos em atividades técnicas e de ensino relacionadas aos problemas ambientais do momento. Diferentes reflexões e práticas observadas evidenciaram a necessidade do exercício teórico na perspectiva de identificar e ressaltar a história e as características principais de um segmento que, no âmbito da geografia, parece indicar, no presente, a constituição de uma abordagem diferenciada (uma corrente/ uma linha de pensamento/) dentro da ciência. [...] A história da sociedade humana do último quarto do século XX encontra-se fortemente marcada pelo debate acerca da questão ambiental, fato que repercute de maneira integral no escopo do conhecimento geográfico (MENDONÇA, 2001, p. 114-115).

De acordo com a pesquisa de Mendonça (2001) fica claro que o meio ambiente tornouse objeto de estudo dos geógrafos nas últimas décadas, mas, ainda há uma forte ligação com a concepção naturalista. Essa concepção naturalista se distancia um pouco da relação homem/natureza fazendo com que o homem seja parte e não elemento da natureza. Mendonça (2001) apud Porto Gonçalves (1989) aborda que o termo Geografia tem uma correlação com o meio ambiente, ou seja, deve-se falar Geografia ou ambiente. Esta, também, correlaciona com o termo meio ambiente e meio geográfico. 
[...] o termo ambiente, eivado que é de uma pluralidade de concepções e conceitos, e presente em acepções tanto científicas, políticas e culturais como em político governamentais, de movimentos sociais gerais etc. Mas num aspecto parece haver concordância: o termo ambiente e ambientalismo empregados na atualidade ligamse a concepções completamente diferentes daquelas de final do século XIX e início do XX. Se naquele momento estavam atrelados diretamente ao estudo da natureza do planeta, hoje liga-se mais aos graves problemas derivados da interação entre a sociedade e a natureza, às relações homem-meio, homem-natureza, físico-humano, homem-homem"etc. [...] $\mathrm{O}$ contexto recente no qual emergem as grandes discussões e desafios ambientais parece não mais permitir ao homem a vivência de situações nas quais ser cientista, intelectual, técnico, profissional e cidadão sejam experiências desconectadas. Para aqueles que vivem no mundo da academia e das instituições de pesquisa um cotidiano de permanente envolvimento com problemas ambientais é, inúmeras vezes, difícil separar o ecológico do ecologismo, o ambiente do ambientalismo. Por seu lado, aqueles imersos nos movimentos ambientalistas estão sempre a demandar suporte científico para a defesa de suas causas (MENDONÇA, 2001, p. 118).

Então, fica claro que, a discussão acerca da geografia abarca e contempla tanto o meio ambiente como as questões ambientais, principalmente, a partir da década de 1980. Sendo assim, essa ciência deixa de tratar o meio ambiente de forma particular e fragmentada (antes de 1980) e passa a tecer uma interligação dos fatos do meio ambiente com o homem, apesar de, às vezes, na prática não ser concretizada esta interligação. Por vários motivos, como: técnico, político, econômico e cultural.

\section{Considerações Finais}

Os problemas sócio-ambientais se agravaram a partir da industrialização, e por fim a urbanização, que no momento atual atinge uma porcentagem de mais de $80 \%$ da população do país morando nas cidades. Isso agravou os nossos espaços urbanos, espaços rurais, os rios e as florestas com mais intensidade a partir da década de 1960. Período da transferência de indústrias pesadas, poluidoras e barulhentas dos países desenvolvidos para o Brasil, principalmente, no governo de Juscelino Kubstichek (JK). O início desse processo começou a partir do momento em que houve a ruptura do sistema de exportação de produtos da agricultura e recursos minerais e passou a produzir bens industrializados, nos anos de 1930, com a derrubada do poder político-econômico das oligarquias para as elites de cunho 
industrial e urbano. Mas essa mudança gerou a concentração de bens e renda, acirrou as desigualdades sociais, provocou a depleção dos recursos naturais, aumentou as favelas urbanas e as favelas rurais agravando o dramático quadro sócio-ambiental do país.

A industrialização estimulou a urbanização nos espaços urbanos (concentração populacional) e também a mecanização na área rural, para aumentar a produção de alimentos, para o consumo urbano e o cultivo de cereais para as exportações. Esse processo provocou o êxodo rural, aumentando as favelas, e por fim, poluindo nascentes, áreas de preservação permanente, áreas de mangues. Esta exclusão gera violência, pobreza e problemas sócioambientais. Essa ocupação desordenada, ilegal é fruto da falta de planejamento, infraestrutura, segregação espacial (concentração de renda) por agentes imobiliários de cunhos especulativos com base no lucro fácil e rápido.

Para combater essa problemática é preciso investir em políticas públicas democráticas para as classes pobres com o intuito de garantir a cidadania por meio do direito à cidade, à qualidade de vida, à educação e à moradia. Os instrumentos de combate a esses males são: Implementação do Estatuto da Cidade, elaboração e implementação de Planos Diretores, uma constituição pró-ativa, zoneamento ecológico econômico e outros que tratem de forma ativa a população negligenciada, e não, de maneira, política eleitoreira e autoritária, que passam as informações de forma passiva e sem diálogo.

\section{Referências Bibliográficas}

ACSELRAD, Henri. Políticas Ambientais e Construção Democrática. In: VIANA, Gilney, et al (Org). O desafio da Sustentabilidade: Um debate sócio-ambiental no Brasil. São Paulo: Fundação Perseu Abramo. 75-96p.2000.

BARBIERI, José Carlos. Desenvolvimento e Meio Ambiente. As estratégias de mudanças da agenda 21. Petrópolis, RJ. Vozes. 159p. 1997.

CAPRA, Fritjof. O Ponto de Mutação: a ciência, a sociedade e a cultura emergente. Tradução Álvaro Cabral. Título original: The Turning Point. São Paulo. Cultrix. 447p. 1982.

DELGADO, Costa Guilherme. Capital Financeiro e Agricultura no Brasil: 1965-1985. São Paulo. Ícone e UNICAMP. . Cap. 1, p. 19-49. 1985.

GOODLAND, Robert. Sustentabilidade Ambiental: Comer melhor e matar menos. In: CAVAlCANTI, Clóvis (org). Meio Ambiente Desenvolvimento Sustentável e Políticas

Públicas. São Paulo. 3ª ed. Cortez: Fundação Joaquim Nabuco.Cap. 17, p. 271-298. 2001.

MENDONÇA, F. Geografia e Meio Ambiente. $7^{\mathrm{a}}$ ed. São Paulo. Contexto. 80p 2004. 
. Geografia Sócio-Ambiental. In: Associação dos Geógrafos Brasileiros

(AGB). Paradigmas da geografia. São Paulo. Terra livre, n.16. 113-132p. 2001.

MORIN, Edgar. $\boldsymbol{A}$ Cabeça Bem-Feita: repensar a reforma, reformar o pensamento. Tradução

Eloá Jacobina. 8a ed. Rio de Janeiro. Bertrand Brasil. 128p. 2003.

MOTA, José Aroudo. O Valor da Natureza: Economia e Política dos recursos ambientais.

Rio de Janeiro. Garamond. 37-65p. 2001.

MÜLLER, Geraldo. Complexo Agroindustrial e Modernização Agrária. São Paulo, Educ e HUCITEC. 149p. 1989.

NEHME, Valéria Guimarães de Freitas. A Pedagogia de Projetos na Práxis da Educação Ambiental: Uma experiência na Escola Agrotécnica Federal de Uberlândia (MG). Dissertação (Mestrado). Universidade Federal de Uberlândia, Uberlândia, 182p. 2004.

SANTOS, Milton. O espaço do Cidadão. São Paulo. Nobel, 142p. 1996. 